\title{
Dare to Think Past the Anthropocene
}

\author{
DANIEL ROSS
}

\begin{abstract}
To refer education to the dates 2030 and 2050, as the UN has done via its "Education for Sustainable Development" and "Futures of Education" initiatives, is to place it in the context of the IPCC's two key deadlines for the reduction of carbon emissions. Yet this immediately leads to a paradox: how can we even begin to conceive or imagine education after 2050 without first recognizing that the current dismal failure to approach these targets stems in no small part from an inability to foster the collective knowledge and will required to take care of this biospheric emergency - and that remedying this inability absolutely depends on a transformation of the conditions of intergenerational transmission and a critique of contemporary education? Rather than being paralysed by this paradox, we must inhabit it as the vector of a new dynamism directed towards the transformation of the way education is conceived and undertaken in the nihilistic depths of the Anthropocene. This will require a renewed understanding of the meaning of both sustainability and diversity, the relationship these bear to reason and technics, and the way this ultimately yet unavoidably calls for a new economic model.
\end{abstract}

KEYWORDS: Bernard Stiegler, Anthropocene, Immanuel Kant, education, sustainable development.

\section{Introduction: 2030 and 2050}

Being invited to reflect on the relationship between education, diversity and sustainability in the context of the years 2030 and 2050, it is obvious that these are the two dates identified in the famous Special Report on anthropogenic climate change released by the IPCC in October 2018, where it was argued that the world must limit global warming to less than 1.5 으 $\mathrm{C}$ above pre-industrial levels. The UN body concluded that the achievement of this goal requires global net anthropogenic $\mathrm{CO}_{2}$ emissions to be reduced by $45 \%$ from 2010 levels by 2030 and to zero by 2050 (IPCC, 2018). Two and a half years later, where do we stand in relation to those goals? Well in March 2021 an Australian report stated that "Limiting climate change to 1.5으 is now virtually impossible" (Australian Academy of Science, 2021, p. 8), and research published in Nature in February claimed that "On current trends, the probability of staying below $2{ }^{\circ} \mathrm{C}$ of warming is only $5 \%$, but if all countries meet their nationally determined contributions and continue to reduce emissions at the same rate after 2030, it rises to 26\%" (Liu \& Raftery, 2021, p. 1). Finally, another recent Australian concludes that "Multiple lines of evidence strongly suggest that we can no longer limit warming to 1.5 으 without significant overshoot and 
subsequent drawdown, and that the global average temperature rise will exceed $1.5 \circ \mathrm{C}$ during the 2030s" (Climate Council, 2021, p. ii).

These are reports and pieces of research that I have selected. Other selections would have been possible, and indeed other researchers have different assessments of the likelihood of various outcomes. So it is not obligatory to believe that $1.5 \circ \mathrm{C}$ is impossible or that there is only a $5 \%$ chance of staying below $2{ }^{\circ} \mathrm{C}$. What is obligatory is to recognise that all statements about goals, intentions, targets, aspirations, commitments, promises, expectations, hopes or dreams have to be seen in the context of a $\mathrm{CO}_{2}$ emissions reality that to this point consists in nothing but year-on-year increases in the number of billions of tonnes of carbon being released into the atmosphere.

That claim - that all statements about and relationships to the future have to be seen in the context of present trends - may sound unduly pessimistic and not terribly "philosophical", projecting a possible future only on the basis of a feeling about present difficulties. Nevertheless, philosophy today can no longer pretend to be divorced from science or technology. Philosophers must take account of this dire scientific probability, but in a way that genuinely tries to respond to it as an emergency, and not just as an excuse either for further chatter or for proclaiming that the time for "thinking" or "theorizing" is past: what is absent are precisely the concepts by which we can understand this failure and begin to address it by aiming at the improbable, if not the virtually impossible. If philosophers have nothing meaningful to say about this, then why should anyone bother to listen to them?

If, then, I nonetheless hope that you will continue to give me your attention, it can only be because I believe that there is, in the context of this emergency, something worth saying about the relationship between education and "sustainability". Whether that belief is justified is something it will be up to you to judge, and the way in which it will be judged is by knowing what difference it makes to how you see what is to be done, and what you do. The worst thing to do would be to indulge in a "talk fest" that ultimately just aped the blather of politicians and other powerful figures for whom responsibility does not seem to consist in matching claimed intentions to actions. Yet nor could taking responsibility consist in maintaining a posture of "resistance": what matters is not to resist, but rather to begin to think, and to care, about how to invent.

\section{Three attitudes to the Anthropocene crisis}

To think about how to invent: for this, we absolutely require an assessment of the present situation. Such an assessment must not just calculate probabilities, but must be a critique, understood as the process of analysis and synthesis called for by a crisis. In the case of climate change, we must begin by acknowledging that this is only one limit towards which the biosphere and globalization seem to be headed, one among many, where each combines with others in a precipitating way, and where addressing only one of these limits always risks accelerating the headlong rush into others. In the case of all of these limits of contemporary atmospheric, ecological, technical, economic, social and political systems, the starting point for critique must be to recognise that ultimately there are only really three possible "attitudes" towards this crisis.

The first attitude consists in concluding that the emergency has gone beyond the point where catastrophe can be avoided: thresholds have been crossed, tipping points reached, and no significant difference can any longer be made. This is to say that there is no longer any collective horizon of a belief in a good future for the systems that form the matrix of our existence, leading to a fatalistic attitude that corresponds to nihilism: nothing is possible,

2

Dare to Think Past the Anthropocene

Futures of Education, Culture \& Nature - Learning to Become 
therefore everything is permitted. To call this nihilism does not prove that it is "false", and it may in fact correspond to the most probable truth of our contemporary situation. Yet to content ourselves with doing no more than adapting to the probable is to accept that this catastrophe is bound to fall upon the heads and shoulders of our children and our children's children. And so, if we do not wish to confine ourselves to tending our own garden as the forest burns, then we are bound to consider the alternatives, however improbable.

The second attitude corresponds to a vision to which the world's public and private powers have pinned their hopes: the vision according to which it is possible to modify the relationship of the technical and social systems to the atmospheric, geological and biological systems of the planet, and to do so without fundamentally transforming the economic model that articulates the exchanges occurring within and between these technical and social systems and that pollutes these atmospheric and ecological systems. This is the notion that it is possible to take care of terrestrial and human life by "decoupling" production and consumption from the carbonization of the atmosphere, and that such decoupling can be extended to all of the other poisons and harms that afflict and threaten the biosphere. On the one hand, this fantasy runs up against the "reality" that emissions have done nothing but rise, that habitat has done nothing but shrink, that biodiversity has done nothing but decrease; on the other hand, the very same fantasy serves to justify the ongoing refusal to examine or respond to the systemic causes of these trends.

What ultimately perpetuates this situation is the quite possibly justified fear that, despite assurances that we can really do this and it isn't that hard, despite being cajoled with the idea that acting now will be much cheaper than having to do more later (Nature, 2018), in fact, to really reduce emissions to zero, reverse the loss of habitat and stem the reduction of biodiversity would entail a very significant risk to the global economy, and could bring who knows what unforeseeable consequences, ranging from famine to authoritarianism to global war? Before dismissing this fear as "alarmist", we should reflect on the idea that lies behind such a "decoupling": the proposition that a global economic system whose economic sustainability depends on a constant and never-ending increase of consumption can be maintained ad infinitum while simultaneously reducing non-renewable energy consumption to zero, and all this without continuing to destroy habitat and biodiversity.

Doing justice to the improbability of such a decoupling, or in other words applying what Jacques Derrida called the aporia of justice (Derrida, 2002, pp. 244-58) to this aporia of sustainability (Ross, 2021, ch. 4), forces us to raise the necessity of a third attitude, which is to consider the real possibility that this global macroeconomic model has reached its limit. When any system reaches its limit, the alternatives are either that it collapses or that, through a transitional and transformational process, it facilitates, more or less violently, the opening of another system, which in this case means another macroeconomic model articulating the relationship between the technical system and social systems, along with the geological, atmospheric and biological systems of the Earth's biosphere. Such transitional transformations are neither impossible nor new: they occur historically whenever a "disadjustment" (Gille, 1986) between the technical system and the social systems is successfully negotiated - collapses do occur, but they are not bound to occur.

But then we must add: if in this case a collapse is to be avoided, it depends on the existence of individual, collective, institutional and organizational will and intelligence capable of negotiating such a transformation. Furthermore, if $1.5 \circ \mathrm{C}$ really is slipping from our grasp, or $2{ }^{\circ} \mathrm{C}$ has only a $5 \%$ probability, or if $\mathrm{CO}_{2}$ emissions have done nothing but rise, and if all of this has occurred despite the warnings of the IPCC, despite the promises and commitments of governments, despite protests and despite the plethora of books about the Anthropocene

3 
(McLemee, 2019) - if all of this has happened despite all of that, it is ultimately because of the failure of individual, collective, institutional and organizational will and intelligence. In other words, transformational re-adjustments of the technical and social system are always possible, but they can become impossible if the conditions of collective will and intelligence are themselves what has been undermined, depleted or destroyed in such a process of disadjustment.

\section{What is education? Endosomatic and exosomatic learning}

This brings us to the question that truly ties the Anthropocene to education: the unsustainability of a global system that tends to destroy will and intelligence, which is to say, care, and the corresponding need to reinvent systems capable of fostering and cultivating them. It is here that the question of education becomes absolutely unavoidable, but it is here, too, that we require a new critique of education, starting from an acknowledgment that education, too, is in crisis. And, to count as a critique, this means that we must first know what education is, and we must secondly know what it is for, in this century that faces this headlong rush into limits. It is by asking these questions that we will be able to understand how the question of sustainability is really the same as the question of diversity, but only on two conditions: (1) that we acknowledge that no sustainability is ever final, and (2) that we know what we actually mean by this word, "diversity".

What is education? In order to survive, many kinds of creatures must, when young, learn lessons from older members of their species, and many creatures must also learn lessons about behaviour through play that amounts to rehearsal of the survival functions they will need when no longer under parental care. Instinctive behaviour, arising as a result of so-called 'natural selection' over thousands if not millions of generations, and "recorded" genetically, is therefore obviously not the whole story of animal behaviour. There are latitudes in the expression of the genetic instincts of animals, and what opens the limited space of behavioural freedom is the fact that individuals of a species possess not only a genetic memory that is inherited from generation to generation, but a nervous memory, a brain, capable of "recording" the lessons of experience, which may then become a constitutive and necessary part of the raising of individuals of that species. Nervous memory thus makes possible new behaviour by an individual who learns a lesson from their individual experience. And, at least among the higher primates, it makes possible a living chain of lessons, passed on from one generation to the next, as was observed among Japanese monkeys on Koshima in 1953, when for the first time a female was seen washing a sweet potato in the sea to improve its taste, an innovation disseminated to others of the troop and transmitted from generation to generation, becoming a normal part of the learned behaviour of the monkeys of that island.

Should we call the transmission of this technique of washing sweet potatoes education, which is to say, are these processes that generate what is usually called culture? Perhaps we should. Why not? After all, this is a modification in behaviour that represents an advance in taste, hence in some way an aesthetic development.

Many people understand the idea that consideration of these questions cannot any longer be a matter of opposing the animal and the human, or nature and culture - this is perhaps the key lesson of the forms of French philosophy and thinking that arose in the 1960s - but what we learn from the philosopher Bernard Stiegler, who himself learned it from André Leroi-Gourhan and Alfred J. Lotka, is that it is a matter of making a distinction, which is not an opposition, between the transmission of lessons that rely on genetics and brains (which we can call endosomatic forms of memory) and the transmission of lessons that rely on genetics and brains and externalized supports (that is, exosomatic forms of memory). This third form 
of memory, exteriorized memory (Leroi-Gourhan, 1993), begins long before humans existed, and occurs in pre-human hominins as a co-evolution of brains, hands and tools, an exosomatic evolution (Lotka, 1945) so that we cannot, strictly speaking, say that one of these rather than another was the driver of this co-evolutionary process (Stiegler, 1998). Long before there are externalized supports dedicated to the conservation of memory and lessons, there are tools, and, in fact, every tool used by hominins functions, deliberately or otherwise, as a kind of memory, in the sense that, for example, a flint chopper or hand axe records the gestures of the hands that fashioned it, which means that, thousands of years later, it becomes possible for researchers to re-learn how to make such tools.

When, much later than the commencement of stone tool production, tools do begin to be produced that are dedicated to the conservation of memory and the exteriorization of mental contents, with the painted caves of the Upper Palaeolithic, then it truly begins to become possible to conserve, transmit, accumulate and transform the lessons of experience, including lessons accumulated by those who lived many generations before my own, and to whom I may not be related by an unbroken chain of either genetic or nervous memory. This develops much further when, later still, these external supports begin to include the means of writing, which opens the possibility, for example, of the transmission of the lessons learned by the founders of geometry, and all of the other disciplines of formal knowledge that require an institutional education that we call schooling. School is essentially an institution in which, through an apprenticeship based on the frequenting of externalized repositories of accumulated past knowledge, it becomes possible to recapitulate the history of this knowledge in condensed form, so that a child can learn in a few years what took centuries or even millennia to be gathered, discovered and invented by human beings of past epochs.

What, then, is the relationship between this notion of education and the transmission of lessons amongst Japanese monkeys on Koshima? Or in other words, what is the same and what is different between forms of learning that are endosomatic (relying on genetics and brains) and forms of learning that are exosomatic (relying on genetics and brains and exomnesic tools)?

What is the same is that the conservation of the lessons of experience is the means by which life of all kinds pursues the struggle against entropy: as we learn from Erwin Schrödinger in 1943 (1992), always and everywhere life is a singular and improbable dynamic process that locally and temporarily defers the overwhelming tendency of the physical universe, which consists in the irreversible elimination of the improbable by the probable and the exhaustion of potential energies. While the lessons learned from the individual experience of a single organism are not conserved genetically, processes of natural selection mean that, across many generations, new forms of improbability can emerge from endosomatic evolution, in the form of the differentiation of new organs and species adapted to the conditions of life at that time and in that locality. The lessons learned by a single organism can indeed be conserved by that organism during its life, in a brain and nervous system that possesses the ability to adapt behaviour on the basis of experience, but, with the death of the organism, those lessons are mostly lost to the species, notwithstanding the possibility of a continuation of certain kinds of behaviour of the kind seen on Koshima.

In the case of exomnesic life, the lessons of the individual member can be saved, accumulated, condensed and developed, and ultimately this, too, is a question of the means of conducting the negentropic struggle for existence against the overarching entropic tendency. This accumulation and development of lessons, however, makes possible the unfolding of a new singular and improbable process, that of the differentiation of new kinds of exosomatic 
organs and the knowledge of their use, in the process of exosomatic evolution that characterizes the kinds of beings that we ourselves are.

What is different, then, is that exosomatic life conducts this pursuit by means other than life, and in particular by the means of memory organs other than those of "living memory". This implies both that new kinds of improbabilities open up for this form of life, the improbable futures made possible by this educated life that is a technical form of life that knows, and that it is prone to eliminate improbabilities by reducing life to new kinds of probables. The opening of exosomatic knowledge - that is, of what the Greeks called noesis - can always close, which we see with those forms of the elimination of the improbable that are the rigidity of dogma and what Nietzsche called levelling or a reduction to averages, in this way foreseeing the standardization and particularization of life and behaviour made possible through the algorithmic use of big data by the platforms of computational capitalism. Whether it is a matter of dogmatization, levelling, standardization or particularization, in each case there is an elimination of the improbable as knowledge is reduced to information, and in particular to computable information, tending to deprive it of its dynamic potential, which is to say, exhausting the social energy of desire that circulates across libidinal circuits, thereby undermining will, intelligence and the possibility of opening new improbable futures.

\section{Grammatization and proletarianization}

Hence there is no education that does not involve the knowledgeable practice of exomnesic retentions, which opens the possibility of every kind of exomnesic protention (Husserl, 1991). All education depends on exomnesic instruments, on technologies of memory, and there can be no conception of the future of education that does not take account of the evolution of these technologies and instruments. Education is an education in knowledge to the precise extent that it is an irreducibly mnemotechnological practice: just as exomnesic technics makes possible the accumulation and transformation of knowledge, so too knowledge is what makes possible both the development of technology and the care that must be taken of this dangerous supplement.

Stiegler conceives this history of exomnesic or retentional technologies as a history of what he calls grammatization, a term coined by the linguist Sylvain Auroux (1994). For Auroux, grammatization refers to the process involved in the transformation of speech, which is temporal, into writing, which is spatial, a process that, especially in the case of alphabetical writing, required the continuous temporal phenomenon of speech to be made discrete, analysable and reproducible as letters. But for Stiegler, grammatization is understood as the spatialization of temporal phenomena in general, and thus in fact starts much earlier than does alphabetical writing, with the materialization and exteriorization of mental contents expressed in the rupestral art I mentioned earlier (Stiegler, 2014). After the invention of writing, it remains little changed for quite some time, until the advent of the printing press that enables the mass printing of the Lutheran Bible that Max Weber will later describe as the origin of the spirit of capitalism in a process that turns this "spiritual" use of printing (which Auroux will describe as the spiritual technologies that accompanied and drove colonialism and its missions) into the "profane" technology of modern account books and accounting methods.

Stiegler's extension of this term, however, applies both to the grammatization of the audiovisual realm that will later occur with radio, cinema and television, and also to the mechanical processes underlying the Industrial Revolution of the nineteenth century. For what made that massive transformation of the technical system possible was not just the new spirit supplied by Luther's printed Bible or the new source of energy supplied by Watt's steam engine, but 
also the instructions programmed into Jacquard's machine, which grammatized the gestures of the weaver, rendering them discrete, analysable and reproducible in the punch cards of the mechanical loom. So too would the gestures of every kind of work and tool-equipped craft be grammatized by industrial machines, thereby creating the great nineteenth-century division of classes between the proletariat and capital, through which the latter dispossesses the former not just of the means of production, but first and foremost of the knowledge of those means, the knowledge of how to make and do things with tools (Stiegler, 2010a).

The real meaning of proletarianization is this destruction of knowledge effected by the exomnesic technologies of the grammatization process. Socrates had more than an inkling of this when he described writing as a pharmakon, which is to say both detrimental and beneficial for memory, but it becomes a systemic reality when industrialization makes it possible to mechanize the process, or in other words, to automate it. Hence: in the nineteenth century we see the grammatization of production with the factory, and the proletarianization of the knowledge of how to make; in the twentieth century we see the grammatization of consumption with marketing, and the proletarianization of all the knowledge involved in customs, cultures and ways of life; and in the twenty-first century we see the grammatization of every kind of knowledge, including the formal and rational disciplines of so-called Western knowledge, and in particular psychological, sociological and educational research, leading to a very general proletarianization in which trust in science and, in fact, in every kind of authority has dissipated to an all-time low, in an epoch often referred to for that reason as the age of post-truth.

\section{The war against education}

It follows from the recognition that we are exosomatic and exomnesic beings, and from the recognition that, for such beings, the pursuit, accumulation, transmission and transformation of knowledge are the very means of the pursuit of life, that there has never been, and there never will be, any form of education for exosomatic beings that is not, in one way or another, an instrumented education: schooling will always be a technological process. The history of education largely reflects the history of these instruments, the history of the retentional systems utilizing technologies of grammatization through which relationships between teachers and pupils are always mediated. There can thus be no good future for education that does not pass through the consideration of the knowledgeable practice of the instruments with which teachers and students will be equipped in 2030, 2050 and beyond.

Nevertheless, the key word here is knowledgeable: being exosomatic and exomnesic beings, we always need knowledge, but we can always lose knowledge - we can always find ourselves falling prey to or getting caught up in one or another process of proletarianization. There is absolutely no reason to assume that, just because a technology is new, it will necessarily be better than a technology that is old (for this or that end, for example, educating children), or will not bring new and potentially greater problems, and certainly there is no reason to assume automatically that the new should replace the old, that the computer or the iPad should replace the blackboard or the textbook or the notebook. Any attempt to take up new tools that fails to carefully consider the pharmacological character of these instruments, that is, the possibility and in fact the necessity that they will not only enable education but also poison it, any attempt that does not also try to take care to minimize this poisonous aspect of education, especially in a twenty-first century in which these instruments are immeasurably more powerful than ever before, but where this also means potentially more powerfully toxic - any attempt to take up new tools in education that does not do these things is bound to produce a crisis in education. 
And this is precisely what has happened to education over the course of the past several decades. What has made it possible? Stiegler makes a distinction between programming institutions, which are the social organizations of mass learning that arose in Europe in the nineteenth century, operating at that time mainly with the retentional system of writing and made possible by the large-scale printing of textbooks, and programming industries, which are what Theodor Adorno referred to as the culture industries, emerging in the twentieth century, and which Stiegler understands as organizations of mass unlearning, operating mainly with the retentional systems associated with the grammatization of the audiovisual (Stiegler, 2010b). Whereas programming institutions have the function of taking care of the transmission of knowledge and the cultivation of care for this knowledge in succeeding generations, a care that makes possible the continuation and transformation of this knowledge, the goal of the programming industries is to short-circuit the programming institutions, to capture the attention of young minds, and to divert this attention from the long-term if not infinite desire for knowledge and towards the short-term if not instantaneous satisfactions of consumption, however much such satisfactions may dwindle, leading to an addictive spiral that can only accelerate processes of proletarianization.

Yet at the time when the programming institutions were confronted with this battle for the minds and spirits of young people, these institutions themselves to a large extent failed to recognize the scale of this battle and the power of the weapons directed against them. A war was and is being conducted against education, by the use of audiovisual and now digital grammatization in the service of marketing and commodification directed at capturing youthful attention and undermining any identification with older generations (and where adolescent rebellion is itself really a mechanism for negotiating the shift from primary identification to adulthood). But instead of recognizing this war and prosecuting it, educational institutions have tended rather to act as if it could be won by a strategy of capitulation.

Symptoms of this failure to take up arms are the increasing acceptance of the idea that attention to teachers, subjects and tasks is something that can be bought only by the means of the culture industry, with lights, sounds, action, changes of scene. Or that only literature deemed 'relevant' to the (assumed) everyday lives of students is worthy or capable of receiving their attention, or that only mathematics problems that relate to the "contexts" of those lives could ever not be 'boring'. In one way or another, such symptoms are reflections of the more general war conducted by marketing: to displace parents and teachers as prescribers for young people, and precisely to invert the relationship between the generations.

Rather than seeing education as a process with the potential to enchant students by opening up past worlds, or worlds of the unfamiliar or the abstract, thereby making possible the eventual discovery and invention of new worlds, this kind of attitude and approach begins with the assumption that attention is always on the verge of being lost because students will always "naturally be attracted to the proliferation of available distractions, that the worlds of past culture and knowledge are mostly dead, and that it is only by appealing to the already familiar that such a loss can ever hope to be prevented. Faced with the systematic attempt to capture attention, and to eradicate its "deep" modes in favour of the "hyper" (Hayles, 2007), such an approach to education only accelerates the process by offering less and less that is worthy of attention. We must, on the contrary begin by recognizing that all culture is composed of, or is a compost of, dead worlds memorialized in exomnesic artefacts, and that it is solely on the basis of this humus, this "noetic necromass" (Stiegler, 2018, p. 107), that new worlds of knowledge and culture can ever be fertilized. To participate in this erasure of the past is to collude in the elimination of time - that is, in the elimination of the possibility of forming a cohesive epoch. 


\section{Kant, Foucault, discipline}

Michel Foucault's great influence on social thought really begins with the publication of Discipline and Punish, which analyses Bentham's panopticon in order to understand how the perpetual possibility of being under surveillance is exploited in order to cause prisoners to internalize the repressive imperatives of the authoritarian institution, thereby disciplining their behaviour (Foucault, 1977). This analysis thus pays close attention to the technologies of bodily submission, but far less to the technologies of writing that form the basis of schooling as the noetic admission to collective knowledge, nor again to those later grammatization technologies that will be exploited by marketing and consumerist capitalism, less repressively than regressively.

Nevertheless, Foucault's account of the prison will be taken up in later research, with and without Foucault, and applied to many other kinds of institutions, leading to the notion of "disciplinary society", an undoubtedly fruitful concept by which it becomes possible to understand the authoritarian and repressive tendencies that any social organization can find itself inhabited by. Yet if one is an authority, does this necessarily imply that one is either authoritarian or repressive? In the case of schools, we must not forget that the word "discipline" has at least three meanings: (1) the disciplining of bodies and behaviour analysed by Foucault; (2) the disciplines of knowledge the desire for which and the capability for which is acquired through education; and (3) the self-discipline necessary to pay attention to these objects of knowledge.

In short, the question of discipline in education is really the question of attention, and this is why Stiegler writes:

In the school analysed by Foucault as a surveillance system, it is not a matter of forming attention [...]. But what Foucault completely neglects here is the role of the teacher [maitre] who is charged with forming it through a discipline that is not that of surveillance but that of integration into the circuits of transindividuation, governed not by norms but by concepts (Stiegler, 2010b, p. 117, translation modified).

Attention is by no means a natural faculty of the human being: the human ability and need to pay attention to objects detached from what for animals would be their instincts, or in other words the human capacity to invest in objects of desire of all kinds, including that form of protentional capacity that is called "will" and especially in those objects of knowledge that are the subjects of knowledge, must always be cultivated, starting from the attention that parents must know how to pay to their children. This is why Kant begins his "Lectures on Pedagogy" by stating that "The human being is the only creature that must be educated", and why he distinguishes the needs of animals - for food, warmth and so on - from the additional need of those exosomatic organisms that are human children for a form of care that he understands as "the precaution of the parents that children not make any harmful use of their powers" (Kant, 2007, p. 437).

For Kant, it is already the case that this need for education arises from the fact that the human being is without instinct:

An animal is already all that it can be because of its instinct; a foreign intelligence has already taken care of everything for it. But the human being needs his own intelligence. He has no instinct and must work out the plan of his conduct for himself. [...] Discipline prevents the human being from deviating by means of his animal impulses from his destiny: humanity (pp. 437-38).

No doubt we would not say exactly this in exactly this way today: in Stieglerian terms, it is not a matter of being with or without instinct. It is not a matter of opposing instinct to human 
freedom, but of the advent of an exosomatic organism whose instincts, or rather drives, can, precisely because of its exosomatic origin, be detached from their aims and reattached to other aims, including to objects that do not exist, yet consist - all those objects of desire that are the "ideas" (on subsistence, existence and consistence see Stiegler, 2011, pp. 89-93).

Nevertheless, for Kant, it is precisely this need for "care and formation" that means that

children are sent to school initially not already with the intention that they should learn something there, but rather that they may grow accustomed to sitting still and observing punctually what they are told, so that in the future they may not put into practice actually and instantly each notion that strikes them (Kant, 2007, p. 438).

This is less a matter of disciplinary submission in the Foucauldian sense than the "organological formation of bodily habits" as a preliminary attentional condition of so much education. What must be added, here, is that even and perhaps especially in these first preparatory steps, where the instruments may be only a desk or a floor (in the case of a dance class, for example), this seemingly almost mechanical discipline must, in fact, if it is to succeed, always be accompanied by, or rather consist of, a process that simultaneously enchants (in Winnicott's sense) the world of the child so that he or she will in one way or another be led to invest themselves in such a cultivation of attention, which is to say, find themselves protentionally directed, wanting to project their noetic and libidinal energies towards a further pursuit of the material and spiritual rewards made possible by the continued cultivation of attention. Far from being antithetical to care, discipline would in this way be its very character and condition.

And we should recall that, a few pages after observing that education begins with learning to become accustomed to sitting still, Kant concludes that "to have trained one's children is not enough, rather, what really matters is that they learn to think" (p. 445). All of this adds up to a conclusion not so far removed from that reached by a young Fran Lebowitz, which she expresses in the form of a piece of humorous advice for seventeen-year-olds:

Think before you speak. Read before you think. This will give you something to think about that you didn't make up yourself - a wise move at any age, but most especially at seventeen, when you are in the greatest danger of coming to annoying conclusions (Lebowitz, 2003, p. 31).

Critical thinking is no doubt one of the most worthwhile capacities to cultivate in young people living in a society in crisis, but what is very often forgotten is that critical thinking must always be accompanied by a capacity for care, itself equally in need of cultivation. This latter capacity depends on entering a process that generates an individual and collective ability to love the world rather than hate it, a love that would be opened up and enchanted by a care-filled educational process. One crucial aspect of the generation of such love and care is for teachers and institutions to know how to enchant students with a love of knowledge, and more specifically with the knowledge contained in disciplines. Education systems must produce teachers capable of such generation and give them the means of cultivating these virtues.

\section{Autonomy and automatism}

How, then, should we think these twin imperatives: the necessity of instilling even the most basic aspects of attention formation, such as being able to sit still and listen, and the necessity of fostering the ability to think, as Kant italicizes it, or (and this really amounts to the same thing) the ability to care, as Stiegler will often italicize it? The model of the disciplinary society lifted from prison and applied as a heuristic with which to critique schooling tends to oppose these two imperatives: the disciplining of bodies in educational institutions automates

10

Dare to Think Past the Anthropocene

Futures of Education, Culture \& Nature - Learning to Become 
behavioural responses and thereby dulls the capacity for the freedom to think. But this opposition of the automatic and the autonomous is precisely what can in no way be maintained by any coherent picture of the educational process.

All of life depends on the maintenance of automatisms, from the perpetually maintained rhythms of the cardiovascular system to the automatic reflex that shrinks from pain. Automatism is the condition of life itself: "feedback loops" are what define the negentropic systems of endosomatic life, and these are, precisely, automatisms. In exosomatic life, however, the automatisms in play are not limited to instinctual loops, but rather extend to all kinds of nonbiological automatisms, which must be learned, and which, in the form of the spirals of knowledge rather than the loops of instinct, make possible the dis-automatization of human behaviour, such dis-automatization being that to which "autonomy" has always really amounted. This is why Stiegler could write:

The noetic brain [...] is essentially the organ capable of acquiring automatisms (reading, writing, counting, playing football, playing the violin, or "playing" like Diderot's actor), and of thus conquering something as an autonomy (the possibility of being a "great actor"), as the anamnesic power to dis-automatize by starting again each time from the originary default of all knowledge that always precedes me - just as the past of Dasein has always preceded it (Stiegler, 2021, pp. 255-56).

Practising scales at the piano or memorizing multiplication tables in early primary mathematics, far from being the repressive disciplining of the musical body or the mathematical mind, are in fact crucial early steps along the road towards the dis-automatization necessary to be a great, or even a good, musician or mathematician, which is to say, not a bad one, these automatisms precisely freeing up the mind and giving it the space to be occupied with something else, that is, with the possibility of playing, composing, thinking or reasoning.

When educational theory and practice abandons the knowledge of the necessity of automatisms (or replaces them with technological automatisms, such as allowing programmable scientific calculators to replace the internalization of the ability to solve more complex problems in later secondary mathematics), and does so in the name of the most vacuous concept of freedom, when it unthinkingly embraces the notion of "allowing the child the freedom to explore and discover", free of such "disciplining", and conjoins this to the ideology of resilience and adaptability, it does nothing more than conform to the emptiest neoliberal paradigm while simultaneously allowing the utter destruction of the educational process that such a neoliberalism demands. Consequently, it is no surprise that so often the "pathways" promised by this kind of eviscerated pseudo-education prove to be mirages and dead ends.

\section{Identity, diversity, sustainability}

One might be forgiven for imagining that all of this amounts to a nostalgic plea for a "return" to "universal reason" against the "relativizing" conceits of a "postmodernism" all too willing to declare itself the enemy of every universality. That would, however, be a misunderstanding of the argument I am putting, founded on a false dichotomy. Nor is it a matter of "blaming" Foucault for the failures of educationalists to take up arms against the forces of neoliberal adaptation. But it is a matter of recognizing that to a large extent children, parents and teachers have been left defenceless and unarmed in a war in which the enemy tendency remains barely visible, because the concepts with which to conceive this crisis are lacking.

From the Stieglerian standpoint, reason is what emerges from a complicated arrangement between autonomy and heteronomy, that is, from a process of the internalization of "heteronomic artifactuality" (ibid., p. 242), or again, from the "mutual diffraction" (Stiegler, 2020, 
esp. 73-77) between the interior milieu constituting a tribe or a society, the exterior milieu constituting the wider cultural world in which that society is embedded, and the technical milieu that supports this heteronomic artifactuality according to the forms of grammatization that are available to it and that produce the "attentional formation" proper to that epoch. This composition of the autonomous and the heteronomous, this complicated articulation of grammatized information and the possibilities of knowledge opened up by it, and this diffraction of the interior, the exterior and the technical - what emerges from all of this as knowledge, reason and thinking, that is, as noesis, can be conceived not as a universality but only as a genuine di-versality of reason, which, in the pursuit of always unfinished knowledge, opens up new chances for bifurcations in reason that continually enrich this diversity. Such a diversity of knowledge and reason, which mirrors at the exosomatic level the biodiversity that constitutes the wealth of endosomatic life, which is "wealth" precisely because without it ecosystems could never be sustainable - such a diversity of knowledge and reason is what alone makes possible the sustainability of a neganthropic cosmos within the anthropic universe, which it can do only because the peaceful contest and cooperation produced by this diversity give rise to the possibility of generating new turns, bifurcations in noetic individuation that are alone what make possible the reinvention of an obsolescent system, one that has reached its limits and is facing collapse, which can happen suddenly, or, as Wolfgang Streeck thinks, may last a long time, as an "otherwise unsustainable" and entropic "interregnum" perpetuated by the desperate activities of "coping, hoping, doping and shopping" (Streeck, 2016, p. 41).

If this diversity can thus never be reduced to any universality, then we must also add that this implies that it is not and can never be a diversity of identities, whether of individuals or groups. Why not? Because the unfinished processes of psychic and collective individuation that arise from the composition of disautomatization and the heteronomy of technical individuation are, precisely, processes of in-dividuation, aiming at overcoming divisions yet constitutively unable ever finally to do so - there are no finished identities, except as the closure of individuation, which amounts to its collapse, the termination of the process. The rise of the so-called "politics of identity" can only be, to the extent that it is premised on the existence of identities rather than processes of identification, a regressive pseudo-politics, regressive with respect to the endless complications of educated, political, noetic and exosomatic life: whether it is a matter of the "right-wing" identities of nationalism or the "left-wing" identities of gender or race, these substantializations can only ever be a way of avoiding the true political questions, which are always about processes, and the true questions of diversity, which are always a matter of the diversity of knowledge, knowledge that never exists but only consists, knowledge that must be fostered, transmitted, pursued and transformed, including the epistemological problem of what counts as knowledge in a perpetually and rapidly changing technical system.

In this sense, the rise or re-rise of identitarian conceptions of social existence must be understood as symptoms of the failure of education and the failure of contemporary society in general to know how to navigate the complexities and diversities of the psychic, collective and technical individuation processes of contemporary life, in an age when the third of these seems destined to overwhelm the first two, thereby also eliminating the conditions of possibility of its own continuation. Such a symptom is itself only one of many arising from a condition of no longer knowing how to care, and, in particular, how to take care of intergenerational relations, in a time where this destruction of the ability to "know what to do" about the raising of children leads adults, as Bernard Stiegler has said, to "themselves behave like children marketing also systemically infantilizing them, that is, depriving them of their autonomy" (Stiegler, 2021, p. 257). This inability and infantility produce what Bernard Stiegler and Greta 
Thunberg both condemn: an immense regression, a generalized irresponsibility of adult generations, both in relation to the fostering of a sustainable di-versality of reason and in relation to the protection of the conditions of a sustainable biodiversity. For Stiegler, Greta Thunberg was a sign - herself a positive symptom of a possibility, however improbable, but where this depends also on the education of Thunberg and her generation, that is, on our duty to try and draw them out towards the open questions that thus far have failed to materialize on centre stage: those of the conditions of the de-proletarianization and the re-noetization without which no de-carbonization will ever be achieved.

Will and intelligence, both individual and collective, have their conditions. As long as educators and policy-makers continue to push or be pushed towards adapting education to the "solutions" offered by global technology companies, so long as these educators and policymakers, and all of us, fail adequately to address both: (1) the problems caused by the massive computerization and marketization of primary, secondary and tertiary education; and (2) the question of if and how grammatization technologies could contribute to dis-automatization, rather than tending to eliminate everything that cannot be reduced to calculable information, the dates of 2030 and 2050 are bound to be merely further milestones along the road of collective failure.

To counter these problems and raise these questions, in theory and in practice, is possible, however, only on the condition of massive investment in research aimed at addressing them, research whose premises must not be those that have presided over the educational capitulation to which I have tried to draw your attention here, and must be those that make possible a bifurcation towards the regeneration of a new wealth of reasons capable of giving us the reason, in all senses of the word, to act. Bernard Stiegler argued that the unsustainability of the current macroeconomic system confronts us with the challenge of finding ways of opening a new dynamic leading past this system, and he shows that this depends on the invention of new computational instruments specifically designed to foster a diversity of knowledge, and through that to make possible genuinely contributory research processes capable of fuelling such a dynamic. Only if Greta Thunberg's more-than-tragic parrhesia, expressed in the phrase, "How dare you!", can in this manner meet up with Kant's injunction, "Dare to think!", could we ever dream of opening up a careful but urgent pathway beyond the blocked horizon whose name has become the Anthropocene.

\section{Literature}

Auroux, S. (1994). La révolution technologique de la grammatisation: Introduction à l'histoire des sciences du langage. Liège: Mardaga.

Australian Academy of Science. (2021). The Risks to Australia of a 3ํㅡ Warmer World. Retrieved from https://www.science.org.au/supporting-science/science-policy-and-analysis/reports-and-publications/risks-australia-three-degrees-c-warmer-world

Climate Council. (2021). Aim High, Go Fast: Why Emissions Need to Plummet This Decade. Retrieved from https://www.climatecouncil.org.au/resources/net-zero-emissions-plummetdecade/

Derrida, J. (2002). Acts of Religion, edited by G. Anidjar. London \& New York: Routledge.

Foucault, M. (1977). Discipline and Punish: The Birth of the Prison, trans. A Sheridan (New York: Vintage.

Intergovernmental Panel on Climate Change (IPCC). (2018). Global Warming of $1.5^{\circ} \mathrm{C}$ : An IPCC special report on the impacts of global warming of $1.5^{\circ} \mathrm{C}$ above pre-industrial levels and

13

Daniel Ross

Futures of Education, Culture \& Nature - Learning to Become 
related global greenhouse gas emission pathways, in the context of strengthening the global response to the threat of climate change, sustainable development, and efforts to eradicate poverty: summary for policymakers. Retrieved from http://report.ipcc. ch/sr15/pdf/sr15_spm_final.pdf

Gille, B. (1986). The History of Techniques, 2 vols, trans. P Southgate \& T. Williamson. New York: Gordon \& Breach.

Hayles, N. K. (2007). Hyper and Deep Attention: The Generational Divide in Cognitive Modes. Profession 2007, 1, 187-99. doi.org/ 10.1632/prof.2007.2007.1.187

Husserl, E. (1991). On the Phenomenology of the Consciousness of Internal Time (1893-1917), trans. J. B. Brough. Dordrecht: Kluwer Academic Publishers.

Kant, I. (2007). Anthropology, History, and Education, edited by G. Zöller \& R. B. Louden. Cambridge: Cambridge University Press.

Lebowitz, F. (2003). Metropolitan Life. Paris: Edition 7L.

Leroi-Gourhan, A. (1993). Gesture and Speech, trans. A. Bostock Berger. Cambridge, Massachusetts \& London: MIT Press.

Liu, P. R., \& Raftery, A. E. (2021). Country-based rate of emissions reductions should increase by $80 \%$ beyond nationally determined contributions to meet the $2{ }^{\circ} \mathrm{C}$ target. Communications, Earth \& Environment, 2(29), 1-10. doi.org/10.1038/s43247-021-00097-8

Lotka, A. J. (1945). The Law of Evolution as a Maximal Principle. Human Biology, 17(3), 16794.

McLemee, S. (2019). Making the Anthropocene. Retrieved from https://www.insidehighered.com/views/2019/04/05/overview-books-anthropocene

Nature. (2018). Curbing Global Warming Could Save US\$20 trillion. Retrieved from https://www.nature.com/articles/d41586-018-05219-5

Ross, D. (2021). Psychopolitical Anaphylaxis: Steps Towards a Metacosmics. London: Open Humanities Press.

Schrödinger, E. (1992). What is Life?, with Mind and Matter and Autobiographical Sketches. Cambridge: Cambridge University Press.

Stiegler, B. (1998). Technics and Time, 1: The Fault of Epimetheus, trans. R. Beardsworth \& G. Collins. Stanford: Stanford University Press.

Stiegler, B. (2010a). For a New Critique of Political Economy, trans. D. Ross. Cambridge: Polity Press.

Stiegler, B. (2010b). Taking Care of Youth and the Generations, trans. S. Barker. Stanford: Stanford University Press.

Stiegler, B. (2011). The Decadence of Industrial Democracies: Disbelief and Discredit, Volume 1, trans. D. Ross \& S. Arnold. Cambridge: Polity Press.

Stiegler, B. (2014). Symbolic Misery, Volume 1: The Hyper-Industrial Epoch, trans. B. Norman. Cambridge: Polity Press.

Stiegler, B. (2018). Qu'appelle-t-on panser? 1. L'immense régression. Paris. Les Liens qui Libèrent.

Stiegler, B. (2020). Noodiversity, Technodiversity: Elements of a New Economic Foundation Based on a New Foundation for Theoretical Computer Science, trans. D. Ross. Angelaki, 25(4), 67-80. doi.org/10.1080/0969725X.2020.1790836

Stiegler, B. (2021). Elements for a Neganthropology of Automatic Man, trans. D. Ross. Philosophy Today, 65(2), 241-64. doi.org/ 10.5840/philtoday2021414397

Streeck, W. (2016). How Will Capitalism End? Essays on a Failing System. London \& New York: Verso. 